\title{
THE ROLE OF PRODUCT PERSONALIZATION IN EFFECTS OF SELF-CONGRUITY VERSUS FUNCTIONAL CONGRUITY
}

Wenling Wang, Guilford College, United States

Rajneesh Suri, Drexel University, United States

Shan Feng, William Paterson University, United States

\begin{abstract}
Generally, consumers can get three types of benefits from brands (Aaker 1996; Keller 2003): functional, experiential, and symbolic. How to deliver these benefits more effectively than competitors is a critical challenge faced by companies that wish to build successful brands and maintain long-term consumer-brand relationships. To shed light on this managerial problem, much research focuses on the relationship between brand benefits and consumer behavior, such as the research on self-congruity and functional congruity (e.g., Aaker 1999; Kressmann et al. 2006; Sirgy et al. 1991; Wysong et al. 2002). Self-congruity refers to the extent to which a brand's personality (image) matches a consumer's self-concept (self-image), which is relevant to the symbolic benefits of a brand (Kressmann et al. 2006; Sirgy et al. 1991; Sirgy et al. 2000). Functional congruity is related to a brand's functional benefits (Sirgy et al. 1991) and refers to the extent to which the functional attributes of a brand meet a consumer's expectations "regarding how the product should perform to accomplish the focal or central goal of the product." (Kressmann et al. 2006, p957) Many scholars have examined the impact of self-congruity and functional congruity on brand evaluation and brand loyalty (e.g., Aaker 1999; Kressmann, et al. 2006; Sirgy et al. 1991). However, the effects of such congruities on consumers' trust in a brand have received little attention.
\end{abstract}

Moreover, Sirgy (1980) examines the moderating role of product personalization in the effect of self-congruity on product preference and purchase intent; this effect is shown to be stronger for products with high personalization than for products with low personalization. Sirgy (1980) defines product personalization as the extent to which a product shows an image of the user or has symbolic associations. Products associated with a strong image of the user have high personalization and are considered as value-expressive products; while products associated with a weak user-image have low personalization and are thought of as utilitarian-expressive products (Locander and Spivey 1978). However, little research has investigated the influence of product personalization on the effects of self-congruity versus functional congruity. Although Sirgy et al. (1991) indicate that functional congruity is a stronger predictor of consumer behavior (e.g., store loyalty, brand attitude, purchase intent) than self-congruity, it is still not clear whether this finding holds across all products and all situations.

Our study contributes to the two aforementioned aspects by exploring the effects of self-congruity versus functional congruity on brand trust for products with different levels of personalization. We conducted two experiments and the results indicate that both self-congruity and functional congruity lead to heightened brand trust and functional congruity has a greater impact on brand trust than self-congruity for both value-expressive products (with high personalization) and utilitarian products (with low personalization), which supports the finding of Sirgy et al. (1991). Furthermore, for utilitarian products, the stronger influence of functional congruity is shown to not be influenced by the time horizon of a consumer's purchase decision.

These findings suggest that communicating brand personality in a way that is consistent with target consumers' personality attributes and meeting their expectations of product performance will contribute to building their trust in the brand. For both utilitarian and value-expressive products, in order to be successful, companies should make every effort to offer consumers' desired functional benefits better than their competitors. Additionally, communicating the congruence of a brand's personality with a consumer's self-concept is also important for developing brand equity and a long-term consumer-brand relationship, especially for value-expressive products.

References available upon request 